The form

$$
\begin{aligned}
\sin ^{2} \frac{1}{2} z & =\sin ^{2} \frac{1}{2}(\varphi-\delta)+\cos \theta \cos \delta \sin ^{2} \frac{1}{2} P \\
& =(1+x) \sin ^{2} \frac{1}{2}(\varphi-\delta)
\end{aligned}
$$

requires a tabulation of $\log \cos \theta$ (which may be available for other purposes) in addition to $\log \operatorname{cosec}^{2} \theta$ and $\log \cot ^{2} \frac{1}{2} \theta$. But there are many variants-and, in every case, details (such as the procedure when some quantities become very large) that require clarification before these methods can be used in practice.

\title{
International Charts
}

\section{N. Pascoe}

IN his Presidential Address Admiral Ritchie ${ }^{1}$ referred to the two series of charts in 79 small-scale sheets which 16 member states of the International Hydrographic Organization have undertaken to produce; some of them will be published this year. This new development, and how it will affect mariners who now use our Admiralty charts, may be of some interest.

The two small-scale charts for ocean and offshore navigation require a comparatively limited effort and with the enthusiasm and interest shown by all participating nations it is expected that both could be completed within a reasonable period, probably before the end of 1974 . When these charts are published it will be possible to withdraw many small-scale Admiralty charts, some of which were originally published more than a century ago and have subsequently received only partial correction, and much criticism as being out-of-date. But it will not usually be possible to replace them chart for chart as each individual new International Chart is published, because replacement of existing charts can best be made when the whole scheme or at least a complete regional area has been completed. This applies not only to the United Kingdom but to all the world charting authorities and will result in their still having to maintain many existing charts until the new coverage is complete. This problem of 'block' replacement, rather than individual chart replacement, will assume serious proportions in the subsequent larger-scale stages of the International Chart.

For the small-scale series, symbolization is limited and the agreed specifications are relatively few, but it will be interesting to see what national variants arise, especially in the generalization of depth contours. When the first series has been completed, the saving of effort in recompilation and re-editing will be welcomed by all authorities who publish small-scale charts and 5-year or 10-year cyclic revision should be possible. The greatest international saving in effort will, however, be in approach and coastal charts and port and harbour plans, where much duplication exists at present and where continuous, heavy correctional maintenance is necessary.

The concept of the International Chart, which was once expected to involve facsimile reproduction by 'printer' nations, is now that of a modified facsimile, where most printer nations will necessarily translate the title and memoir into the national language and make other language alterations necessary to conform to national charting practice. It is also anticipated that printer nations will add 
their own national chart numbers as well as the INT. number. With the increase in scale many standardization problems will arise, some affecting symbolization in which significant differences, e.g. in buoyage symbols, still exist, but mostly in abbreviations where it seems doubtful whether much progress will be made as this is a language problem. Ultimately, agreed specifications for the larger scale international charts will influence national charts of domestic waters.

Modified facsimile reproduction will permit multi-printer use of any International Chart with little additional national effort, but the reproduction of the existing charts published by I.H.O. member nations is not a practical proposition for the following reasons :

(i) Lack of uniformity in chart size often makes reproduction printing difficult or impossible.

(ii) Reproduction of the largest scale national chart will result in too many charts.

(iii) Existing 'second' scales are not generally suitable for reproduction and use as 'first scale' charts.

(iv) The use of many colour printings by several nations which chart only their national coasts is unsuitable for international use as it is desirable to keep separate colour printings to a minimum.

For the larger scale International Chart it will, therefore, be necessary to agree on standard charts and sizes designed primarily to satisfy the needs of international shipping, i.e. for coastal navigation and entry into ports open to international trade. Such an international scheme would not include the largest scale charts designed for national shipping, except in ports and certain constricted areas. In the present metrication programme for Admiralty charts the second scale coastal chart, generally on a scale of about ${ }^{\prime}$ : 200,000, is being developed as a possible largest scale coastal chart for international use, additional details being included.

Deciding the minimum number of charts required for the extension of the International Chart to coastal navigation and entry into international ports will be difficult as national views on chart coverage vary, but hydrographic offices will at least be interested in any new scheme for charts for their coastal waters, especially the possibility of participation in a joint international effort.

The agreed small-scale scheme for ocean charts (Stage I) involves less than roo sheets : sixteen nations are participating in their production and generally the charts are uncomplicated, the greatest problem being their compilation from many and sometimes conflicting sources. But the larger the scale the more complicated the chart and the larger the number involved. Even for a minimal scheme of coast approach charts on a scale of about $I: 750,000$, coastal charts at about I : 250,000 and 'international' port and harbour plans (Stages 2 and 3), it is probable that a total of the order of 1500 charts would be required. The Admiralty Chart coverage in waters covered by national charts of other nations approximates to an international scheme, and these probably account for about 40 per cent of the total present world chart coverage of about 3500 separate charts, or about 6000 if every separate plan is included. The physical size of the problem of any larger scale International Chart scheme is evident. But it is in the largest scale charts and port plans that the most serious duplication now exists.

It may be necessary to set up regional commissions to develop the larger scale International Chart on the lines of the North Sea Hydrographic Commission, 
these regional commissions to include not only national authorities in the area but also nations which at present publish a 'world' or 'part-world' coverage. It may be less attractive to many nations which chart only their own waters and have no intention of publishing charts of other areas. The possible replacement of their second scale coastal series by a new scheme, with an unaccustomed size and specifications designed for international use, may be regarded not only as expensive but unnecessary from the national standpoint. In these circumstances it may be that the 'world-wide' charting nations which at present publish separate charts of these areas, and have so much to gain from avoiding duplication of effort, will have to consider sharing among themselves the compilation and production in any agreed International Chart scheme. Even if the larger scale extension of the International scheme were ultimately shared only among the present world-wide charting authorities they would benefit from an appreciable saving in effort. It may be necessary for these authorities to duplicate both a national and an international chart coverage over their own coasts. In the United Kingdom the problem could arise if two International Charts on $1: 30,000$ to cover Spithead, the Solent and Southampton Water were added to the national coverage of five charts at $I: 20,000$.

The need for an international series of charts is obvious; the ever-increasing mass of information requires that unnecessary, costly and time-consuming duplication should be minimized. Effective regional schemes may be agreed, but the sustained impetus to produce 'block' areas of new International Charts within a reasonable time will depend on many factors, the availability of additional resources above those required for the continuing maintenance of existing national charts.

Other cooperative ventures in international cartography have experienced the intransigent problems of time, effort and attempted standardization, as for example in the production of the International Map of the World at a scale of 1: 1 million and the similar series by the International Civil Aviation Organization. The production of the International Chart will also be affected by the fact that all nations already publish or have access to all the charts they need, and this may make production less imperative. With the International World Map and the I.C.A.O. map, initial production is still the problem; with the International Chart the problem is the over production of existing coverage and the need for less duplication of effort in an area of ever-increasing maintenance problems.

That charts overlap each other and standardization is thus more necessary, and that publication to be of real value must be in self-contained blocks of charts for regional areas, are factors which tend to make an agreed scheme of International Charts more complicated than that of butt-joining 'individual' maps. But all national hydrographic offices realize the advantage to the mariner of charts which are nationally up-to-date for all the world's waters. This is the objective of the International Chart.

\section{REFEREN CE}

1 Ritchie, G. S. (1972). International cooperation in hydrography. This Journal, $25,2$. 